\title{
A practical rockfall risk model for open pit mines using the time-space concept
}

\author{
J Venter AngloGold Ashanti Ltd, Australia \\ ECF Hamman AngloGold Ashanti Ltd, Australia
}

\begin{abstract}
A number of papers have recently dealt with the topics of economic risk and safety risk in open pits based on larger scale instabilities with more latency (warning time). Rockfall is, however, a low latency failure mechanism and as such, requires separate treatment. This paper presents a practical approach to quantifying rockfall risk based on real measurable data, which allows the model to be calibrated over time. A model is presented that readers can apply in software such as Microsoft Excel and to demonstrate, a practical example is provided. The practical example quantifies the risk for a real slope with and without controls, and demonstrates how factors such as rockfall fences, batter berm configurations, personnel exposure and vehicles can be accounted for to optimise slope design.
\end{abstract}

Keywords: rockfall risk model, safety, exposure, personnel risk, vehicular risk, time-space

\section{Introduction}

Risk-based design acceptance criteria, such as the well-known Probability of Failure are preferred to single point estimates such as Factor of Safety (Terbrugge et al. 2006) for a number of reasons. The reason of particular interest to this paper is the ability to convert probabilities into risk acceptance criteria that enables either company specific risk acceptance criteria or industry or governmentally accepted risk acceptance criteria, such as those summarised by Wesseloo \& Read (2009) for use in geotechnical design problems, to be used. These criteria vary depend on the type of problem being considered, i.e. safety or economic in nature. To this effect, the authors of this paper have developed an economic risk model (Venter \& Hamman 2018b), as well as a safety risk model (Venter \& Hamman 2018a) for geotechnical design purposes. The safety risk model (Venter \& Hamman 2018a) is tailored to failure mechanisms that allow some level of latency (warning time) which can be exploited by a mining company to achieve the relevant safety targets.

Latency is available for all geotechnical failure mechanisms from approximately batter scale and larger, but smaller failure mechanisms such as rockfall often do not provide latency and must be controlled using other methods. Examples of such methods are good blasting and batter cleaning practices, batter and berm configuration design, engineering controls such as drape meshes and rockfall fences, and limiting exposure of personnel to rockfall risk especially during periods of high rockfall frequencies caused by rainfall and wind. This paper aims to address this problem by presenting a rockfall risk model for use in open pit mining and civil engineering applications based on the time-space (TS) concept presented by Fruin \& Benz (1984) for urban pedestrian crossing design. The model borrows concepts from other work such as Hoek (2007), Lateltin (1997), Barnichon (2018) and Fruin \& Benz (1984) and assembles them in such a way that a suitable result is achieved. The model can also be used to present the output in a Geotechnical Model for Rapid Integration (GMRI) (Hamman et al. 2017). An example of a GMRI is shown in Figure 1, in which each grid block can be assigned the various properties of the rockfall model. 


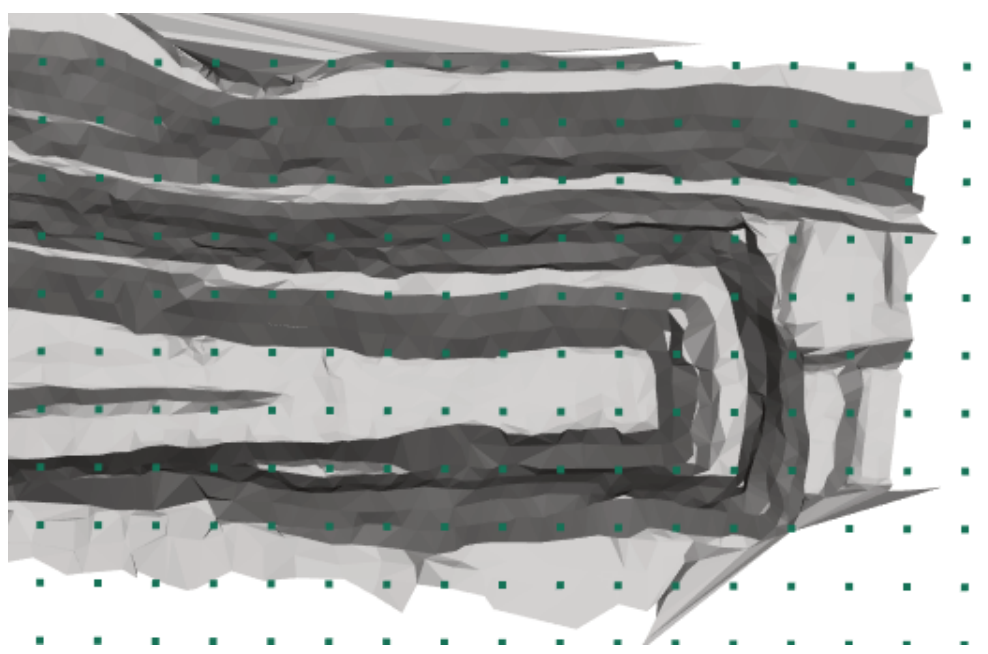

Figure 1 Example illustration of a Geotechnical Model for Rapid Integration. Each grid point represents a node to which rockfall model parameters are assigned (the underlying triangulation shown is an as-built wireframe)

The proposed model is presented first and is then followed by an example application and discussion.

\section{$2 \quad$ Proposed model}

To maximise the useability of a rockfall model, it is necessary to be able to present an output that is comparable to design acceptance standards but that also reflects the effects of different types of controls. It is also desirable to have a model that allows calibration of inputs through measurement or recording of data over time. To accommodate these requirements, a model is needed that incorporate the following probabilistic $(\mathrm{P})$ elements:

- $\mathrm{P}$ (rocks dislodging for each GMRI block).

- $\mathrm{P}$ (rocks reporting to the GMRI block being considered, given they have dislodged).

- $\mathrm{P}$ (rocks hitting personnel, infrastructure or equipment).

To accommodate the GMRI, the model is built around a framework consisting of square blocks of surface area for the terrain being considered (Figure 1). In other words, the open pit or development terrain is divided into square blocks with a value corresponding to each of the input nodes being assigned to each square block. The model is then evaluated for each square block and the results visualised in plan.

The model solutions for dealing with these elements are presented one at a time in the following sections. The final section of this chapter combines all the model elements and summarises the complete model.

\subsection{Rockfall frequency}

The first element to be considered is the $\mathrm{P}$ (rocks dislodging for each GMRI block). In the model, this element is considered using a frequency of rockfall as it is easily measured by recording rockfalls in a pit or from a slope. It is even better if the rockfall source's GMRI block can be recorded as well, as this information can help identify rockfall source hot spots. For new slopes, it also provides a starting value to assign rockfall frequencies to GMRI blocks based on similar GMRI blocks from existing slopes. Attributes that can be used to identify similarity are degree of weathering, slope angle, blast quality ratings, photographs from visual inspection, etc., and allows simple conversion to a probability.

From a rockfall control point of view, however, it is necessary to remember that the rockfall frequency can be changed by removing rocks through scaling, by changing the batter berm configuration or by pinning rocks through anchoring, shotcrete or mesh. While it is difficult to predict the numeric result of such control measures, an estimate can be made by comparison with known GMRI blocks and scaling from there. 
The advantage of using a rockfall frequency in open pit mining as opposed to a return period as used by some Federal Swiss Agencies in the Alps (Lateltin 1997) is that the mathematics of return periods do not work well for rocks emanating from the same GMRI block more than once a year. The reason is that the likelihood simply becomes $100 \%$ and sensitivity to frequency changes between, for example, once a year and twice a month is lost. As a result, for mining purposes and other high frequency sources, it is more useful to consider frequency.

Once the frequency of a rock reporting to a given GMRI block is determined, it is simply a matter of converting it to a probability using the Poisson distribution for comparison to design acceptance standards.

\section{2 $\quad \mathrm{P}$ (reporting to the location being considered)}

The $\mathrm{P}$ (reporting to the location being considered) is the easiest of the inputs to obtain as it is the only input that rockfall simulating software can supply. This model was developed to be independent of simulation software, however, the following factors need consideration before any software is selected for this model:

- Rockfall tends to be a three-dimensional problem and as this model is based on a square grid overlying the site as a GMRI, preference is given to three-dimensional software such as RocPro3D (Barnichon 2018) and Trajec3D (Basson 2019a).

- The shape of rocks are important and contribute significantly to the variation in coefficients of restitution, often obtained through back-analysis using point models. Preference is therefore given to software that can include the shape of rocks.

- The software must allow for definition of rockfall sources for each square block and also be able to report the number of rocks moving through each square output. An example of such software is RocPro3D (Barnichon 2018).

Once the number of rocks reporting to each square block is known, the $\mathrm{P}$ (at least one rock dislodging from slope) can be calculated using the Poisson distribution given in Equation 1 below:

$$
P[\text { at least one rock dislodging }]=1-\frac{\left(e^{- \text {frequency }}\right)\left(\text { frequency }^{0}\right)}{0 !}
$$

The equation inputs have already been adjusted to show that one calculates the probability of having zero rocks reporting to a GMRI block and then deducts that from 1 to reflect one, two, three, etc., rocks. For practical use, Equation 1 simplifies to Equation 2:

$$
P[\text { at least one rock dislodging }]=1-\left(e^{- \text {frequency }}\right)
$$

Note that the choice of units for the frequency is up to the user to select although rocks per year is usually employed. For conversion to corporate risk standards, the project life or life-of-mine can also be employed. Incidentally, the assumption made by Lateltin (1997) for Federal Swiss purposes is 30 years, to reflect a generation.

It is also in the rockfall frequency for a given GMRI point that items such as rockfall fences and mattresses are accounted for by direct modelling in the rockfall software. Such engineering controls will change the number of simulated rocks and potentially also the size of rocks that will report to different squares.

In the model, however, because of the use of the TS concept, such calculations are not needed as summation of the TS requirements for the number of rocks provides the probability of a rock strike directly.

\section{3 $\quad \mathrm{P}$ (rocks hitting personnel, infrastructure or equipment)}

$\mathrm{P}$ (rocks hitting personnel, infrastructure or equipment)-given that a rockfall occurs and reports to the GMRI square being considered-is very simply the exposure of personnel or equipment. To put it in other words, a comparison of the TS resource taken up by rocks with that taken up by personnel, infrastructure or equipment. A rigorous calculation was first proposed by Fruin \& Benz (1984) who define the TS concept for the design of pedestrian walkway crossings. Fruin \& Benz (1984) favoured the TS approach as it could consider intersection size, pedestrian speed, pedestrian size and number and direction of pedestrians. The 
TS approach is considered appropriate here as it allows for the summation of rockfall risk for a number of rocks as well as a number of pedestrians, moving plant and fixed plant. In addition, the principle of superposition applies in that the TS requirements from multiple rockfall sources, design scenarios or personnel and building scenarios can simply be summed to determine the total risk. It also produces the same results if applied to the example presented by Harr (1987, p. 187). In reality, the likelihood of the sand particle passing through the sieve in the Harr $(1987$, p. 187) example is simply a special case of the problem of colliding objects without time and in two dimensions. While the Fruin \& Benz (1984) TS method can be used to calculate the probability of objects intersecting in four dimensions ( $X, Y, Z$ and time) and therefore presents the general case.

In essence, the TS concept is based on the notion that the total spatial resource available for a pedestrian crossing is given by the length $\times$ breadth $\times$ time period under consideration, i.e. if a pedestrian crossing is, for example, $10 \mathrm{~m}$ wide, $20 \mathrm{~m}$ long and the model is constructed in $15 \mathrm{~min}$ intervals, then the total TS available is $(10 \times 20 \times 15=3,000) 3000 \mathrm{~m}^{2}$ minutes. If a pedestrian of $1 \mathrm{~m}^{2}$ then walks through the crossing and takes 10 seconds to walk through, that pedestrian consumed $(1 \times 10 / 60=0.17) 0.17 \mathrm{~m}^{2}$ minutes of TS. In theory, there is capacity for $(3,000 / 0.17=17,647) 17,000$ pedestrians to walk through in our 15 minute interval. This total capacity calculation assumes that all pedestrians walk through in 10 seconds and consume only $1 \mathrm{~m}^{2}$ with no space in-between. In practice, of course, allowance needs to be made for changed spacing such as walking speed changes, different pedestrian sizes, etc. At such dense packing, walking speed comes to a standstill, similarly to what one can see at sport stadium exits after the game and pedestrian walkway capacities toward the exits drop. Such allowances are presented by Fruin \& Benz (1984) but are not part of the scope of this paper.

The TS concept is expanded here to calculate the probability of a rock colliding with the objects in the GMRI square being considered. One can expand the TS concept to include height as well but from a practical perspective, a rock coming off a highwall and flying over a vehicle is still counted as a near miss, and so height is excluded and the TS model developed in three dimensions.

As a result, TS for a rockfall remains:

$$
\text { Time-space }=\text { length } \times \text { width } \times \text { time }
$$

TS is measured as $\mathrm{m}^{2}$ years for the rockfall case. The 'years' unit for time is to allow comparison with the design acceptance charts summarised by Wesseloo \& Read (2009) but other units can be used if convenient.

The total TS available for a GMRI square in a year is given by Equation 4:

$(\text { GMRI square side length })^{2} \times$ time

For example: a 20 by $20 \mathrm{~m} \mathrm{GMRI} \mathrm{square} \mathrm{has} \mathrm{a} \mathrm{TS} \mathrm{capacity} \mathrm{of} 400 \mathrm{~m}^{2}$ years $(20 \times 20 \times 1)$.

A single human with plan area of $1 \mathrm{~m}^{2}$ working in a GMRI square for $308 \mathrm{hr}$ shifts in a year consumes a TS of $1 \times(30 \times 8 / 8760)=0.0274 \mathrm{~m}^{2}$ years (assuming 8,760 calendar hours per year, not work hours).

Similarly, a $1 \mathrm{~m}^{3}$ rock falling and taking 1 second to travel through the GMRI square consumes $(1 \times 1 /(365 \times 24 \times 3,600)) 3 \times 10^{-8} \mathrm{~m}^{2}$ years. Compared to the TS consumed by the human above, the TS consumed by a single $1 \mathrm{~m}^{3}$ rock is relatively small. The relevance of this observation is demonstrated in the following paragraphs.

To calculate the probability of intersection, the TS capacity is now compared to the TS consumed by all personnel, equipment and infrastructure (together labelled 'Targets' in Equation 5) under consideration, and that consumed during a single rockfall event. The equation for the likelihood of impact during a single rockfall event is simply a TS variant of the equation presented by Harr (1987) and is presented as Equation 5:

$$
P(\text { Rock Impact: Rockfall Occurs })=\frac{T S_{\text {Targets }}+T S_{\text {Rocks }}}{\text { Total Time-Space in GMRi Square }}
$$

Which for the example calculations given above result in $\left(0.0274+60 \times 10^{-8}\right) / 400=6.8 \times 10^{-5}$ likelihood of the personnel being hit by a rock in that GMRI square during a given year. It is tempting to sum all the 
potential rockfalls in a year using Equation 5 but this would be incorrect as each rockfall constitutes a separate trial. Consequently, the rockfall frequency must be considered using Equation 2, which is the Poisson distribution. Also notice that since the TS for targets and rocks are summed, and targets tend to be present for much longer periods of time than fast moving rocks, the calculation is not sensitive to the time taken for rocks to travel through the square and an assumption of 1 second will produce adequate results in most cases. The calculation is, however, sensitive to rock size, a reasonable estimate of which is needed.

\subsection{Complete rockfall model}

In summary, applying the rockfall model comprises the following steps:

1. Define the GMRI square blocks across the entire site under consideration.

2. Define a rockfall frequency dislodging from each square. Naturally, many squares, such as those in the pit floor, will have zero frequencies assigned while those on steep blocky slopes with toppling joint sets will have high frequencies. Calculate the likelihood of a rock being present in each square using Equation 2.

3. Model an adequate number of rocks to quantify the likelihood of a rock reporting to each GMRI block emanating from each rockfall source using the selected rockfall model. If a large number of GMRI source blocks are required but the geometry is similar such as for a long section of pit with similar batter berm configurations, the number of GMRI source blocks modelled can be reduced by taking advantage of slope similarities. The principal of superposition applies in the TS part of the model for different rock fall sources so the results can be added together in the GMRI after the rockfall simulation, saving significant modelling time. This assumes that a single frequency of rockfalls is used for all sources, which is typical for most mine sites.

4. Calculate the total amount of TS available for each GMRI block using Equation 4.

5. Calculate the total amount of TS required for each rock size considered for each GMRI block by calculating the TS for each individual block or modelling scenario based on the block size and speed using Equation 3. Then sum the TS requirements for all rock sizes for each GMRI block. If different rock sizes are assigned different frequencies, each size needs to be considered separately and cannot be summed here.

6. Calculate the total amount of TS needed by personnel, equipment and infrastructure inside each GMRI block, again using Equation 3. Assumptions can be made regarding working hours. By controlling access to high hazard zones, the TS for potential rockfall targets can be reduced with the resulting risk reduction defined.

7. Calculate the probability of a rockfall hit, given a rockfall occurs, for each GMRI block using Equation 5.

8. Multiply the result of Point 2 above by that of Point 7. This gives the likelihood of a rock dislodging from the slope and hitting the target under consideration.

9. Compare the results of Point 8 with the design acceptance criteria of your choice and decide on remedial actions if and where needed.

\section{Example application}

The example application presented here consists of part of the footwall slope of an open pit with a single rockfall source modelled. The pit shell is real but the source is fictitious. The trajectory modelling was carried out in Trajec3D (Basson 2019a) and the TS modelling in Microsoft Excel. The final visualisation was carried out in GEM4D (Basson 2019b).

The GMRI calculation sheet that converted the trajectory paths to TS values for each GMRI grid point is presented in Figure 2. In this figure, the coordinates for each GMRI grid point are on the left, followed by a 
count of the number of rocks reporting to that coordinate, the sum of TS required for all rocks reporting to that GMRI block, the TS needed for personnel (in this case a single individual working 200 days per year), the likelihoods of encountering a rock or a person in each GMRI block, and (on the far right) the P(Impact) for each GMRI block.

\begin{tabular}{|c|c|c|c|c|c|c|c|c|c|c|c|}
\hline 4 & A & B & C & D & $\mathrm{E}$ & $\mathrm{F}$ & G & $\mathrm{H}$ & 1 & J & K \\
\hline \multirow{2}{*}{1} & \multicolumn{5}{|c|}{ Inputs } & $=1-(\operatorname{EXP}(-D 3))$ & from Rockfall model & $=1^{*} 200 /(365)$ & $=10^{*} 10$ & $=(\mathrm{F} 3+\mathrm{G} 3) / \mathrm{H} 3$ & $=\mathrm{F} 3^{*} \mathrm{G}^{*} \mathrm{~J} 3$ \\
\hline & Easting & Northing & Elevation & $\begin{array}{c}\text { Rockfall Frequency } \\
\text { (rocks/year) }\end{array}$ & $\begin{array}{c}\text { Rock Diameter } \\
\text { (m) }\end{array}$ & P(Rockfall) & $\begin{array}{l}\text { \% Modelled Rocks } \\
\text { through GMRI Block }\end{array}$ & $\begin{array}{c}\text { TS_Personnel } \\
\text { (m² Year) }\end{array}$ & $\begin{array}{c}\text { TS } \\
\text { Avaliable }\end{array}$ & $\begin{array}{c}\text { P(Impact: } \\
\text { Rockfall occurs) }\end{array}$ & $\mathrm{P}$ (Impact) \\
\hline 139 & 4900 & 18100 & 1580 & 1 & 1 & $63 \%$ & $0.0 \%$ & 0.55 & 100 & $0.55 \%$ & 0.00000 \\
\hline 140 & 4910 & 18100 & 1580 & 1 & 1 & $63 \%$ & $0.0 \%$ & 0.55 & 100 & $0.55 \%$ & 0.00000 \\
\hline 141 & 4920 & 18100 & 1580 & 1 & 1 & $63 \%$ & $0.0 \%$ & 0.55 & 100 & $0.55 \%$ & 0.00000 \\
\hline 142 & 4930 & 18100 & 1580 & 1 & 1 & $63 \%$ & $0.0 \%$ & 0.55 & 100 & $0.55 \%$ & 0.00000 \\
\hline 143 & 4940 & 18100 & 1580 & 1 & 1 & $63 \%$ & $0.0 \%$ & 0.55 & 100 & $0.55 \%$ & 0.00000 \\
\hline 144 & 4950 & 18100 & 1580 & 1 & 1 & $63 \%$ & $0.8 \%$ & 0.55 & 100 & $0.56 \%$ & 0.00003 \\
\hline 145 & 4960 & 18100 & 1580 & 1 & 1 & $63 \%$ & $0.8 \%$ & 0.55 & 100 & $0.56 \%$ & 0.00003 \\
\hline 146 & 4970 & 18100 & 1580 & 1 & 1 & $63 \%$ & $3.1 \%$ & 0.55 & 100 & $0.58 \%$ & 0.00012 \\
\hline 147 & 4980 & 18100 & 1580 & 1 & 1 & $63 \%$ & $0.0 \%$ & 0.55 & 100 & $0.55 \%$ & 0.00000 \\
\hline 148 & 4990 & 18100 & 1580 & 1 & 1 & $63 \%$ & $0.0 \%$ & 0.55 & 100 & $0.55 \%$ & 0.00000 \\
\hline
\end{tabular}

Figure 2 Rockfall Geotechnical Model for Rapid Integration grid points

The probabilities of impact are presented as coloured GMRI grid points in Figure 3, with Figure 4 showing the underlying pit shell. Note that, due to the small probability values, the scale is multiplied by $10^{5}$. For instance, 97.4 at the top of the scale means $0.097 \%$ probability or 0.00097 probability expressed as a fraction.

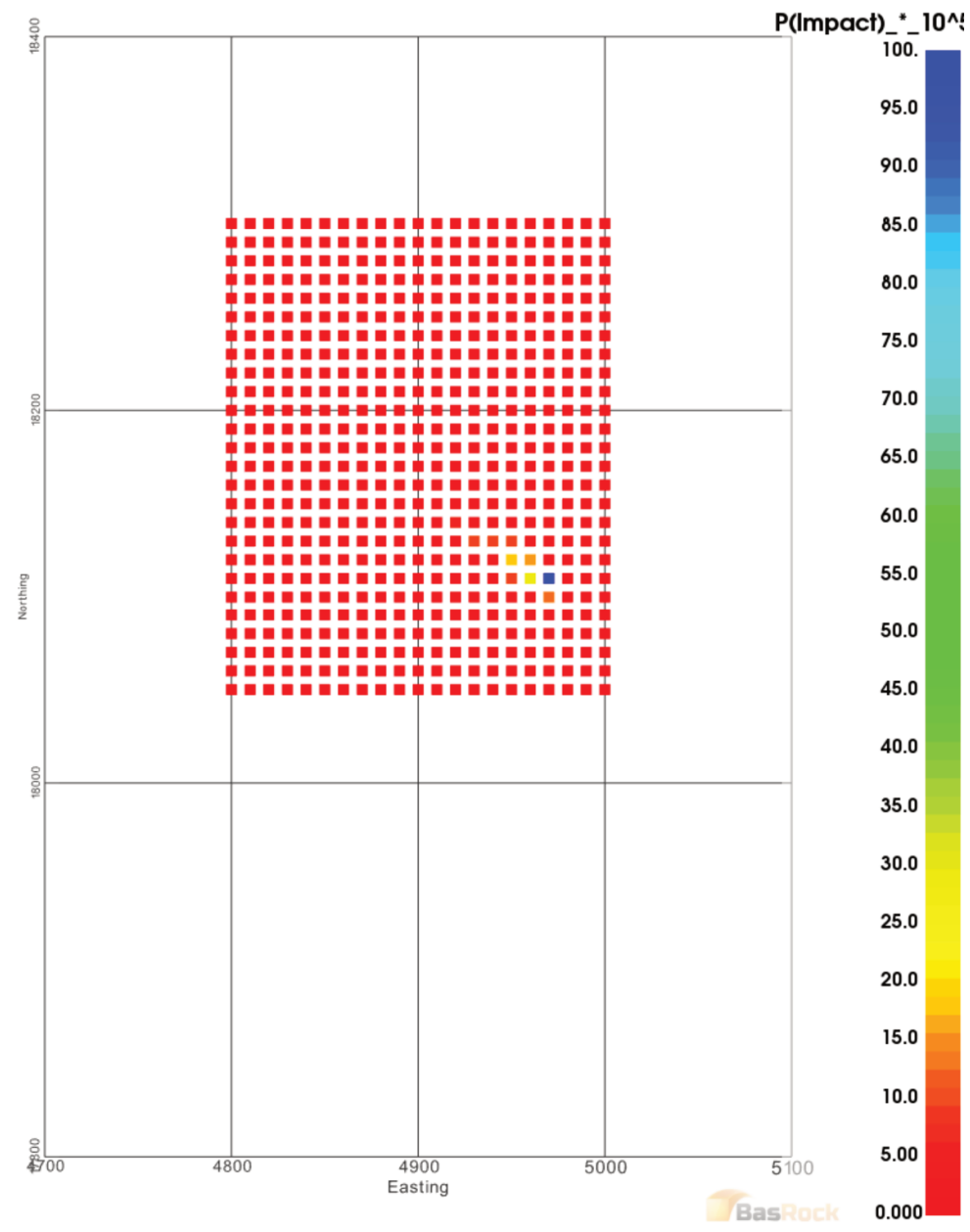

Figure 3 Rockfall Geotechnical Model for Rapid Integration grid points (scale is multiplied by $10^{5}$ in percent; i.e. 97.4 at top is $0.097 \%$ ) 
Figure 4 shows that pit coloured according to the $\mathrm{P}(\mathrm{Impact})$, however, the plan view does not make it easy to see the colour contours so Figure 5 shows an oblique view for clarity.

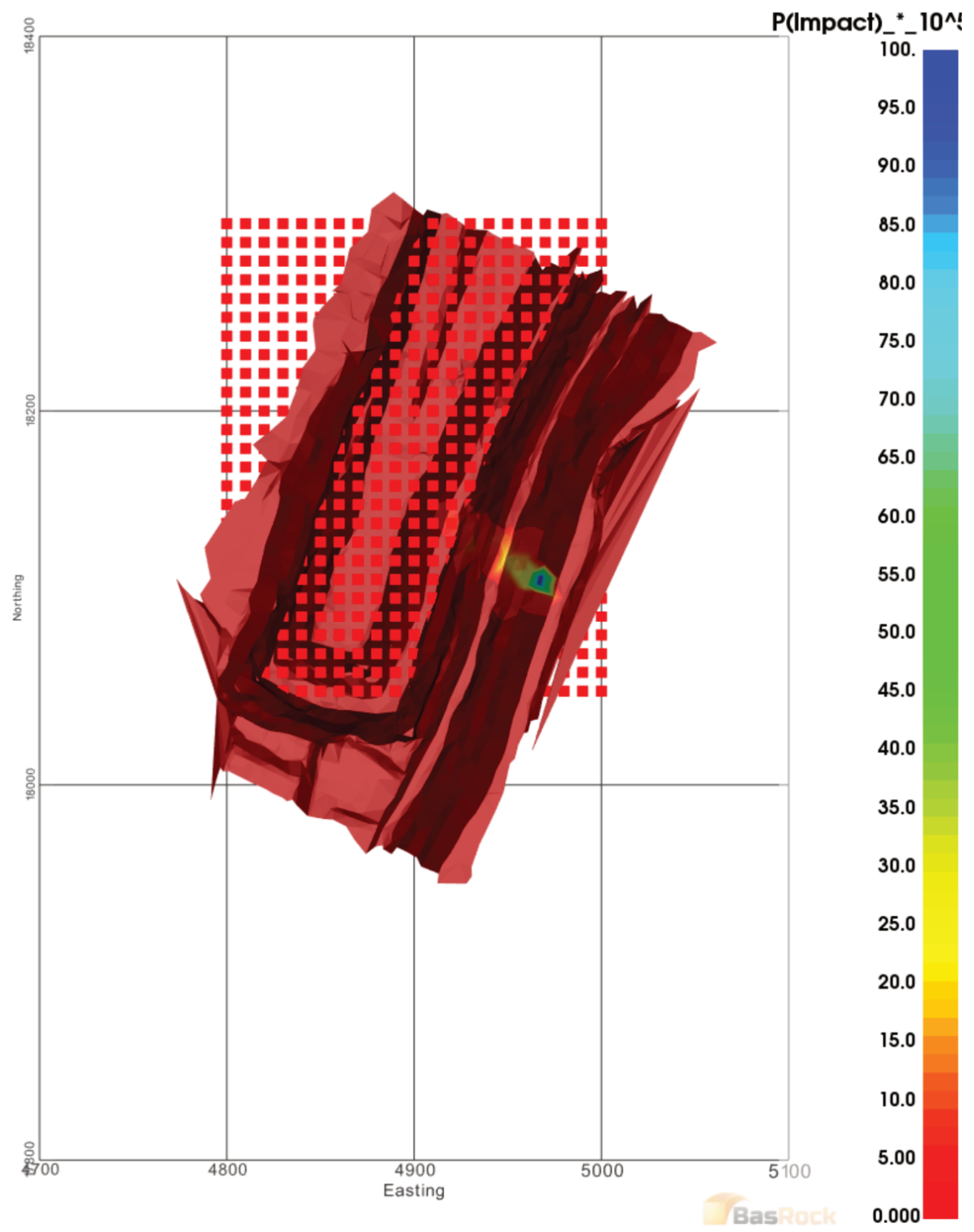

Figure 4 Rockfall Geotechnical Model for Rapid Integration grid points overlying pit 


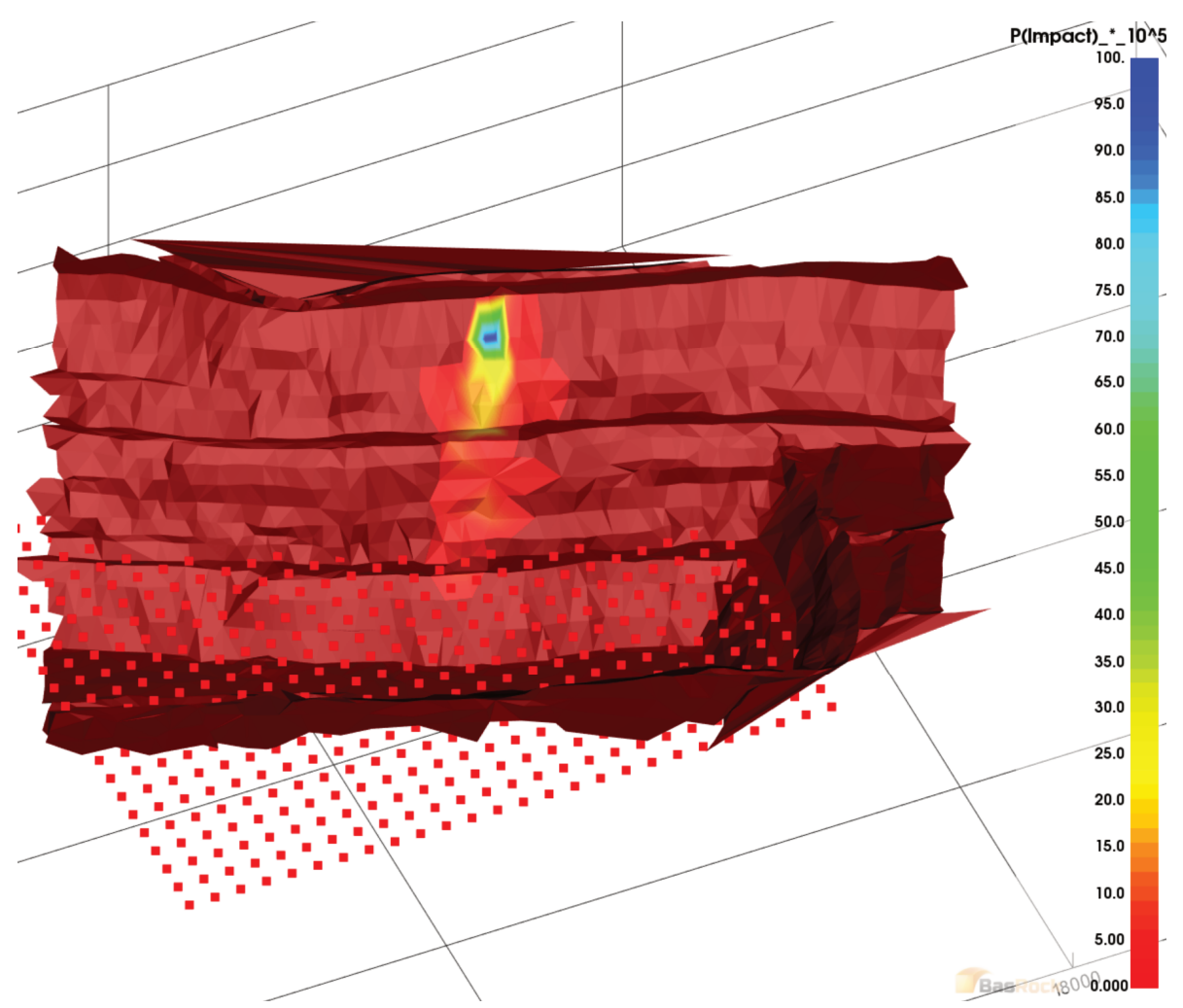

Figure 5 Geotechnical Model for Rapid Integration P(Impact) projected onto pit triangulation oblique view

Figure 6 shows the final result from which it is clear that for this particular rockfall source, rocks are very unlikely to reach the pit floor. Naturally, this simple example does not cover all potential rockfall sources but demonstrates that the TS calculation can be used successfully.

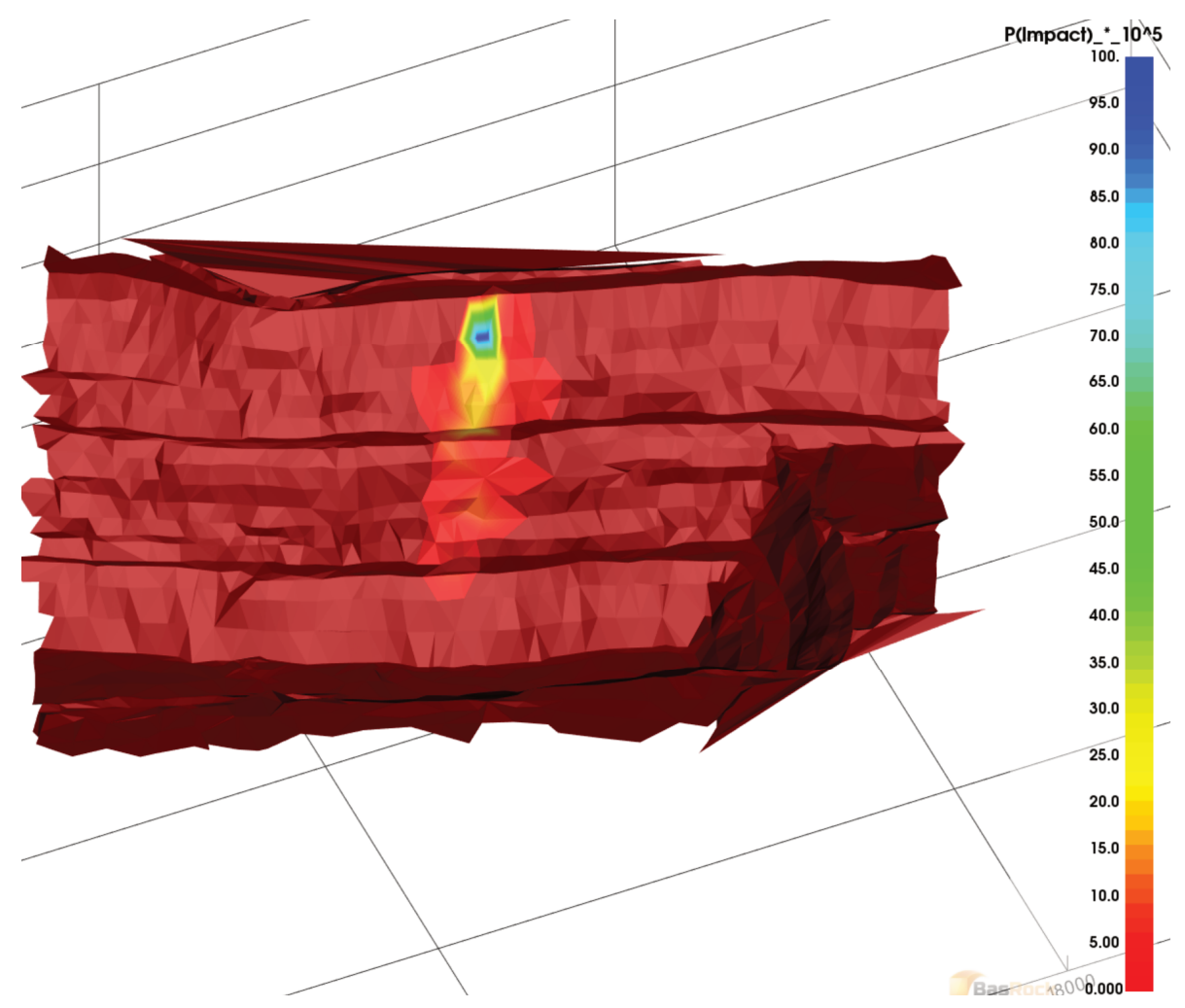

Figure 6 Final result $\mathrm{P}(\mathrm{Impact})$ contour map for a single rockfall source 


\section{$4 \quad$ Conclusion and further work}

This paper presents a new way of processing rockfall data beyond the trajectory modelling stage, that can be used to present the data in a GMRI (Hamman et al. 2017) format for easy decision-making and comparison with existing design acceptance criteria regardless of origin. The simple example shown demonstrates the process but is not a rigorous, fully-fledged, slope design.

In conclusion, the TS concept can be successfully used to calculate the likelihood of impact for rocks on personnel, infrastructure and equipment using a GMRI framework. This facilitates easy communication and decision-making. It also has the advantage of allowing superposition, i.e. the ability to add risk from different rockfall sources and scenarios as well as personnel and equipment scenarios. This paper demonstrates the concept but does not show a fully developed example but only a technology demonstrator. As a result, it is suggested that a real world example is worked through and presented as a follow up paper.

\section{References}

Barnichon, J 2018, RocPro3D, version 5.7.4, computer software, RocPro3D, Saint Cyr-en-Val, http://www.rocpro3d.com/accueil_en.php Basson, F 2019a, Trajec3D, version 1.8.3, computer software, Basrock, Perth, www.basrock.net

Basson, F 2019b, GEM4D, version 1.7.2, computer software, Basrock, Perth, www.basrock.net

Fruin, J \& Benz, G 1984, Pedestrian Time-Space Concept for Analyzing Corners and Crosswalks, Transportation Research Board 959, Washington DC, http://onlinepubs.trb.org/Onlinepubs/trr/1984/959/959-003.pdf

Hamman, ECF, du Plooy, DJ \& Seery, JM 2017, 'Data management and geotechnical models', in J Wesseloo (ed.), Proceedings of the Eighth International Conference on Deep and High Stress Mining, Australian Centre for Geomechanics, Perth, pp. 461-487, https://doi.org/10.36487/ACG_rep/1704_33.2_Hamman

Harr, M 1987, Reliability-Based Design in Civil Engineering, Dover Publications, New York.

Hoek, E 2007, Practical Rock Engineering, Rocscience Inc., Toronto, viewed 3 March 2020, https://www.rocscience.com/assets/ resources/learning/hoek/Practical-Rock-Engineering-Full-Text.pdf

Lateltin, 0 1997, Dangers naturels: Recommandations 1997: Prise en compte des dangers dus aux mouvements de terrain dans le cadre des activités de l'aménagement du territoire (1997 Recommendations: taking into account the dangers due to ground movements within the framework of spatial planning activities), Bureau Felix Frank, Berne, http://www.planat.ch/ fileadmin/PLANAT/planat_pdf/alle_2012/1996-2000/Lateltin_1997_-_Prise_en_compte_des_dangers.pdf

Terbrugge, P, Wesseloo, J, Venter, J \& Steffen, $\mathrm{O} 2006$, 'A risk consequence approach to open pit slope design', Journal of the South African Institute of Mining and Metallurgy, vol. 106, pp. 503-511.

Venter, J \& Hamman, E 2018a, 'A temporal safety risk model for open pit slope management', Proceedings of the 2018 International Symposium on Slope Stability in Open Pit Mining and Civil Engineering, Asociacion Nacional De Ingenieros De Minas/Colegio Oficial De Ingenieros De Minas Del Sur, Seville.

Venter, J \& Hamman, E 2018b, 'Determining the optimum slope angle using an integrated mine planning approach', Proceedings of the 2018 International Symposium on Slope Stability in Open Pit Mining and Civil Engineering, Asociacion Nacional De Ingenieros De Minas/Colegio Oficial De Ingenieros De Minas Del Sur, Seville.

Wesseloo, J \& Read, J 2009, 'Acceptance criteria', in J Read \& P Stacey (eds), Guideline for Open Pit Slope Design, CSIRO, Collingwood, pp. 221-236. 
